\title{
Benefits of Artesunate versus Quinine in the Treatment of Children with Severe Malaria at the National University Teaching Hospital of Cotonou
}

\author{
Godonou Gratien Sagbo1*, Laeticia Zohoun², Gilles Bognon'1, Joseph Agossou3, \\ Caroline Padonou${ }^{1}$, Yévèdo Tohodjèdé ${ }^{2}$, Florence Alihonou ${ }^{2}$, Blaise Ayivi ${ }^{2}$ \\ ${ }^{1}$ Pediatric Unit, Oueme/Plateau Regional University Teaching Hospital (CHUD O/P), Porto Novo, Benin \\ ${ }^{2}$ Pediatric Unit, National University Teaching Hospital (CNHU-HK), Cotonou, Bénin \\ ${ }^{3}$ Mother and Child Department, Faculty of Medicine, University of Parakou, Parakou, Benin \\ Email: *godsagbo@yahoo.fr
}

How to cite this paper: Sagbo, G.G., Zohoun, L., Bognon, G., Agossou, J., Padonou, C., Tohodjèdé, Y., Alihonou, F. and Ayivi, B. (2017) Benefits of Artesunate versus Quinine in the Treatment of Children with Severe Malaria at the National University Teaching Hospital of Cotonou. Open Journal of Pediatrics, 7, 156-163.

https://doi.org/10.4236/ojped.2017.73019

Received: May 3, 2017

Accepted: August 8, 2017

Published: August 11, 2017

Copyright $\odot 2016$ by authors and Scientific Research Publishing Inc. This work is licensed under the Creative Commons Attribution-NonCommercial International License (CC BY-NC 4.0). http://creativecommons.org/licenses/by-nc/4.0/ (c) (7) \&) Open Access

\begin{abstract}
Introduction: Severe malaria is one of the leading causes of death in Sub-Saharan African countries, and artesunate is recommended as a first-line treatment by the Word Heath Organization (WHO.). Objective: Identify the advantages of artesunate compared with quinine in the treatment of severe malaria in children. Methods and patients: This study was a cross-sectional, descriptive and analytical study focused on children hospitalized for severe malaria in the CNHU who were treated with quinine or artesunate. Findings: The hospital-based frequency rate of severe malaria in pediatric patients was estimated to be $28.3 \%(\mathrm{n}=848)$. One hundred five children were treated with artesunate, and 743 were treated with quinine. The mean age of the children was 47 months old. The primary signs of severity were anemia $(n=776)$, neurological manifestations $(\mathrm{n}=309)$ and hemolysis $(\mathrm{n}=137)$. The average duration of treatment was 1.95 days for artesunate versus 2.45 days for quinine, and the difference was statistically significant $(p=0.001)$. The average length of stay (ALOS) in the hospital was 5 days for the artesunate group versus 5.75 days for the quinine group, and the difference was statistically significant $(p<0.001)$. Six of the children who received artesunate died, whereas 24 children who treated with quinine died. The total average cost of healthcare was 50,600 FCFA (77 euros) per child treated with artesunate versus 57,100 FCFA (87 euros) per child treated with quinine. Conclusion: The treatment of severe malaria with artesunate is superior to quinine-based treatment.
\end{abstract}




\section{Keywords}

Severe Malaria, Quinine, Artesunate

\section{Introduction}

Severe malaria is a global public health issue, particularly in Sub-Saharan Africa [1]. According to the WHO, the primary victims of severe malaria are children under 5 years of age [2] [3] [4]. In-hospital lethality remains high in many SubSaharan African countries [5] [6] [7]. To reduce that lethality, the WHO recommended in 2013 that severe malaria be treated with artesunate as first-intention therapy and quinine as second-intention therapy [1]. Indeed, the results of several studies such as South East Asian Quinine Artesunate Malaria Trial (SEAQUAMAT) group showed that parenteral artesunate reduced mortality in adults patients with severe malaria by over a third compared with quinine [8].

In 2012, the in-hospital lethality of severe malaria in the pediatric unit of CNHU-Cotonou was estimated at 13.2\% [9]. The use of artesunate began in December 2013 in this unit in parallel with the use of quinine. Eight months after the introduction of artesunate, we assessed the progress made with respect to patient outcomes to identify the benefits associated with artesunate use compared with quinine.

\section{Patients and Methods}

The present study was a cross-sectional, descriptive and analytical study conducted from January 1 to July 31, 2014, that involved children aged 1 month to 15 years who were admitted to the Pediatric Unit of the Hubert K. Maga National University Teaching Hospital of Cotonou for severe malaria. Severe malaria was defined as a blood smear positive for Plasmodium falciparum in a child with one or more signs of severe malaria according to the World Health Organization [1]. Severe malaria was treated either with injectable artesunate intravenous followed by artemisinin-based combination therapy (ACT) (Arthemeter-Lumefantrin tablet) or injectable quinine followed by quinine tablets. Patients in the quinine arm were given infusions of $10 \mathrm{mg} / \mathrm{kg}$ every 8 hourly. Artesunate $2.4 \mathrm{mg} / \mathrm{kg}$ bodyweight was given on admission, then at $12 \mathrm{H}, 24 \mathrm{H}$ and thereafter once daily until oral medication could be taken reliably. The oral therapies were performed when the child was able to drink, and treatment lasted seven days, regardless of the molecule used.

Recruitment was comprehensive using data from hospitalization records. The data were collected with a data-processing sheet built with hospitalization file data. The distribution of the children in both groups was random because it depended on the availability of artesunate intravenous in the pharmacy of the hospital at the time of the study, quinine being always available. Moreover, it was theirs parents who had to cover all the costs of drugs and laboratory tests. 
Children younger than 15 years were included if they had blood-smear positive for Plasmodium falciparum, and in the admitting physician's clinical opinion, they had severe malaria, and they or their attendant relative or guardian gave fully informed written consent.

Patients were not included if there was a convincing history of full treatment with parenteral quinine or an artemisinin derivative for more than 24 hours before admission.

The study variables were age, type of severe malaria, type of malarial treatment, duration of parenteral treatment, length of hospital stay, death and average cost of treatment according to the antimalarial treatment used. The data (managed in a confidential manner) were retrieved and processed using SPSS 21 software. Pearson's Chi-square test was applied when the number was above or equal to 5, Yates' Chi correction test was applied when the number was between 5 and 2.5, and Fischer's exact test was applied when the number was less than 2.5 .

\section{Findings}

During the study, 848 children with severe malaria were identified out of a total of 2425 admissions for a hospital-based frequency rate for severe malaria of $28.3 \%$. Of the 848 children involved, 743 were treated with quinine, and 105 were administered artesunate followed by ACT. The sex ratio was 1.12. The patient distribution by age according to the treatment received is presented in $\mathrm{Ta}$ ble 1.

The mean patient age was 47 months, regardless of the type of malaria treatment, and there was no statistically significant difference in the mean patient ages in the two treatment groups. The study included 622 children under five years old $(73.3 \%)$

The primary signs of severe malaria in both groups were anemia, neurological disorders and hemoglobinuria, as indicated in Figure 1. There was no statistically significant difference between the two groups.

The average duration of parenteral treatment was 1.95 days in the artesunate treatment group versus 2.45 days in the quinine treatment group, which represented a statistically significant difference $(p=0.001)$. The distribution of children according to the type and duration of parenteral treatment is indicated in Table 2.

Table 1. Age distribution according to treatment received.

\begin{tabular}{cccc}
\hline Age & $\begin{array}{c}\text { Artesunate IV Group } \\
\text { (\# of patients) }\end{array}$ & $\begin{array}{c}\text { Quinine IV Group } \\
\text { (\# of patients) }\end{array}$ & $\begin{array}{c}\text { Total } \\
\text { (\# of patients) }\end{array}$ \\
\hline$<$ 12 months & 11 & 51 & 62 \\
12 to 60 months & 65 & 505 & 570 \\
$>$ 60 months & 29 & 187 & 216 \\
Total & 105 & 743 & $\mathbf{8 4 8}$ \\
\hline
\end{tabular}




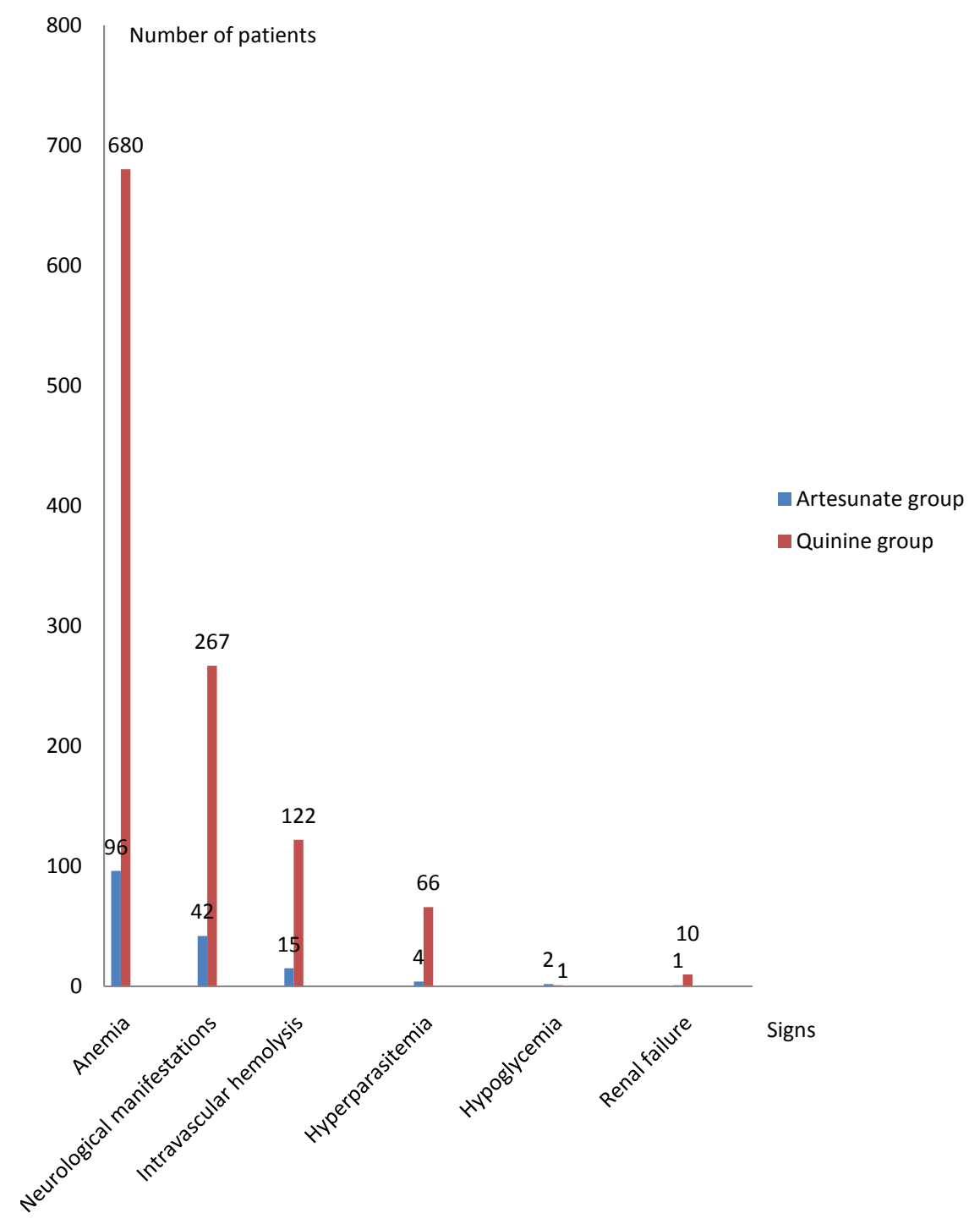

Figure 1. Signs of severe malaria.

Table 2. Duration of parenteral treatment according to treatment type.

\begin{tabular}{cccc}
\hline $\begin{array}{c}\text { Duration of parenteral } \\
\text { treatment (days) }\end{array}$ & $\begin{array}{c}\text { Artesunate } \\
\text { (\# of patients) }\end{array}$ & $\begin{array}{c}\text { Quinine } \\
\text { (\# of patients) }\end{array}$ & $\begin{array}{c}\text { Total } \\
\text { (\# of patients) }\end{array}$ \\
\hline $1-2$ & 81 & 404 & 485 \\
$2-3$ & 14 & 247 & 261 \\
$>3$ & 10 & 92 & 102 \\
Total & 105 & $\mathbf{7 4 3}$ & $\mathbf{8 4 8}$ \\
\hline
\end{tabular}

$p<0.001$

The average length of stay in the hospital was 5 days for the artesunate treatment group versus 5.75 days for the quinine treatment group, which represented a significant difference $(p<0.001)$. Table 3 indicates the distribution of children according to the treatment received and length of stay. 
Table 3. Length of hospital stay according to treatment type.

\begin{tabular}{cccc}
\hline \multirow{2}{*}{$\begin{array}{c}\text { Length of } \\
\text { hospital stay (days) }\end{array}$} & $\begin{array}{c}\text { Type of Treatment } \\
\text { (\# of patients) }\end{array}$ & $\begin{array}{c}\text { Quinine } \\
\text { (\# of patients) }\end{array}$ & $\begin{array}{c}\text { Total } \\
\text { (\# of patients) }\end{array}$ \\
\cline { 2 - 4 } $1-3$ & 29 & 205 & 234 \\
$4-7$ & 56 & 436 & 492 \\
$8-14$ & 16 & 92 & 108 \\
$>14$ & 4 & 10 & 14 \\
\hline Total & 105 & 743 & 848 \\
\hline$p<0.001$. & & &
\end{tabular}

Six of the 105 children who received artesunate died, whereas 24 of the 848 children who received quinine died, but the difference was not statistically significant $(p=0.07)$.

The total average cost of artesunate treatment was 50,600 FCFA (77 euros) per child versus 57,100 FCFA (87 euros) for quinine treatment.

\section{Discussion}

Complying with the WHO recommendations, the CNHU Pediatric Unit introduced intravenous artesunate in the treatment of malaria because of its easier use and improved patient survival relative to quinine treatment [1]. This research study does confirm some of these benefits of artesunate. In this study, the hospital-based frequency of severe malaria was $28.3 \%$, which similar to the 29.8\% ( $\mathrm{n}=409)$ observed in Tanzania in 2012 [10]. In Togo in 2002 and Senegal in 2007, respective hospital-based frequencies of $4.37 \%(\mathrm{n}=361)$ and $6.4 \%(\mathrm{n}=$ 162) were reported, respectively; these figures are much lower than those detected in this study [11] [12]. The study period for the present study included the rainy season, and malaria is holoendemic in Benin, may explain these differences. The mean age of the children involved in our cohort was 47 months old, and the majority of children were less than 5 years old $(73.3 \%)$. This age group represents the group most commonly affected by severe malaria according to several research studies [6] [13] [14]. The predominance of that age group may be due to the disappearance of innate immunity provided by the presence of fetal hemoglobin, poor food diversification secondary to poverty, and the late acquisition of an immune response to malaria [15]. In Senegal, according to two studies performed in 1999 and 2007, the children aged 5 to 10 years were the most likely to be affected by severe malaria [11] [16]. The authors suggested that this pattern was characteristic of intermediary areas of malaria such as Senegal. We observed no statistically significant difference in response to artesunate or quinine with respect to age. Regardless of age, both products remained effective. Severe anemia was the most common sign of severity, consistent with reports by other studies [5] [14] [17]. This high frequency may be associated with the pre- 
valence of iron-deficiency anemia in $30 \%$ to $60 \%$ of children under 5 years in tropical Africa [18]. Furthermore, as CNHU is the national referral hospital, certified blood is more commonly available at the hospital during periods of blood shortages relative to peripheral hospitals. Neurological manifestations were the second-most common severe malaria symptoms identified in a previous study within the same unit [19]. There was no statistically significant difference with respect to the signs of malaria severity with respect to the treatment used. However, we did observe a statistically significant difference with respect to the duration of parenteral treatment and the length of hospital stay. Artesunate seems to be associated with decreased length of parenteral treatment and decreased hospital stays in several studies [20] [21] [22]. The authors of these studies have argued that artesunate treatment is superior with respect to improvements in general patient conditions, reductions in the duration of an altered state of consciousness, frequency of seizures during treatment, length of stay and lethality. In this study, we observed no significant differences with respect to lethality rates in the two groups. In addition to the length of stay, which was reduced with artesunate treatment, the average cost of hospitalization was lower for artesunate treatment relative to quinine. This cost reduction represents an addition benefit, particularly given that a universal insurance system has not yet been instituted in Benin and given that the cost of the children's treatment is entirely borne by their parents. The limitations of this work were the absence of matching between quinine and artesunate treatment, the duration of the study which reduced the sample size and the absence of a multicentre study

\section{Conclusion}

The treatment of severe childhood malaria with artesunate is superior to quinine treatments. These benefits include reductions in the parenteral treatment duration, the length of hospital stay and the average cost of treatment. In light of these benefits, the use of artesunate should be widespread but well-controlled to avoid resistance problems.

\section{References}

[1] World Health Organization (WHO) (2013) Management of Severe Malaria-A Practical Handbook. Third Edition, WHO, Geneva.

[2] Robert, W. (2015) Global Malaria Eradication and the Importance of Plasmodium Falciparum Epidemiology in Africa. Snow BMC Medicine, 13, 23.

[3] World Health Organization (2014) The African Malaria Report, Tech. Report WHO/CDS/ MAL/2014, 1093, Geneva.

[4] Dondorp, A.M., Fanello, C.I., Hendriksen, I.C., et al. (2010) Artesunate versus Quinine in the Treatment of Severe Falciparum Malaria in Africa Children (AQUAMAT). Lancet, 376, 1647-1657.

[5] Mokenhaupt, F.P., Ehrhardt, S., Burkhardt, J., Bosomtwe, S.Y., Laryea, S., Anemana, S.D., Otchwemah, R.N., Cramer, J.P., et al. (2004) Manifestation and Outcome of Severe Malaria in Children Northern Ghana. The American Journal of Tropical 
Medicine and Hygiene, 71, 167-172.

[6] Adonis-Koffy, L., N’do, B. and Timité-Konan, A.M. (2004) Clinical and Biological Aspects of Severe Malaria in Childhood in a Tropical Hospital, in Abidjan (Côte-d'Ivoire). Arch Pediatr, 11, 53-59.

https://doi.org/10.1016/j.arcped.2003.09.037

[7] Mabiala-Babelaa, J.R., Ollandzobo, L.C., Ikoboa, E.R., Nikaa, B.G., Diatewaa, G. and Moyen, G. (2015) Outcome of Severe Anemia Due to Malaria in Congolese Children. Arch Pediatr, 22, 323-328.

[8] South East Asian Quinine Artesunate Malaria Trial (SEAQUAMAT) Group (2005) Artesunate versus Quinine for Treatment of Severe Falciparum Malaria: A Randomized Trial. Lancet, 366, 717-725.

[9] Sagbo, G.G., Alao, M.J., Lalya, F.H., Dagbozounkou, B., Bagnan-Tossa, L., d'almeida, M. and Ayivi, B. (2012) Morbidity and Mortality of Childhood Severe Malaria in Six Hospitals of Benin. Bénin Médical, 50, 34-38. https://doi.org/10.1016/S0140-6736(05)67176-0

[10] Kalinga, A., Mayige, M., Kagaruki, G., Shao, A., Mwakyusa, B., Jacob, F. and Mwesiga, C. (2012) Clinical Manifestations and Outcomes of Severe Malaria among Children Admitted to Rungwe and Kyela District Hospitals in South-Western Tanzania. Tanzania Journal of Health Research, 14, 1-9.

https://doi.org/10.4314/thrb.v14i1.2

[11] Gbadoé, A.D., Kini-Caussi, M., Koffi, S., Traoré, H., Atakouma, D.Y., Tatagan-Agbi, K. and Assimadi, J.K. (2006) Evolution of Severe Pediatric Malaria in Togo between 2000 and 2002. Médecine et Maladies Infectieuses, 36, 52-54.

https://doi.org/10.1016/j.medmal.2005.10.006

[12] Camara, B., Diagne-Gueye, N.R., Faye, P.M., Fall, M.L., Ndiaye, J.L., Ba, M. and So, H.D. (2011) Severity Criteria and Prognostic Factors in Childhood Malaria in Dakar. Médecine et Maladies Infectieuses, 41, 63-47. https://doi.org/10.1016/j.medmal.2010.09.001

[13] Liosimba, L.J., D’Alessandro, U., Donnen, P. and Wilmet, D.M. (2012) Clinical Aspect and Outcome of Suspected Severe Pediatric Malaria. Médecine et Maladies Infectieuses, 42, 315-320. https://doi.org/10.1016/j.medmal.2012.05.008

[14] Dzeing-Ella, A., Nze Obiang, P.C., Tchoua, R., Planche, T., Mboza, B., Mbounja, M., Muller-Roemer, U., Jarvis, J., et al. (2005) Severe Falciparum Malaria in Gabonese Children: Clinical and Laboratory Features. Malaria Journal, 4, 1.

https://doi.org/10.1186/1475-2875-4-1

[15] Pasvol, G., Weatherall, D.J. and Wilsonn, R.J.M. (1977) Effects of Foetal Haemoglobin on Susceptibility of Red Cells to Plasmodium Falciparum. Nature, 270, 171-173. https://doi.org/10.1038/270171a0

[16] Camara, B., Diouf, S., Diagne, L., Fall, L., Ba, A., Ba, M., Sow, D. and Kuakuvi, N. (2003) Children's Severe Malaria in Senegal Hospital Setting. Médecine et Maladies Infectieuses, 33, 45-48. https://doi.org/10.1016/S0399-077X(02)00014-8

[17] Adedemy, J.D., Agossou, J., Alao, M.J., Noudamadjo, A. and Ayivi, B. (2015) Role of Severe Anemia and Hypoglycemia in Severe Malaria's Mortality in Children in a Pediatric Ward in Parakou (Benin). Mali Médical, 30, 19-24.

[18] Bagnan-Tossa, L., Sagbo, G.G., Alihonou, F., d’Almeida, M., Lalya, F., Koumapkaï, S. and Ayivi, B. (2013) Cerebral Malaria in Children: Epidemiological, Clinical, Therapeutic and Outcome in the Pediatric Department of the Hubert K. Maga Teaching Hospital of Cotonou. RAMUR, 18, 37-43. 
[19] World Health Organization (2000) Management of Severe Malaria-A Practical Handbook. 2, Annex 3, World Health Organization, Geneva.

[20] Dondorp, A.M., Fanello, C.I., Hendriksen, I.C., Gomes, E., Seni, A., Chhaganlal, K.D., Bojang, K., Olaosebikan, R., et al. (2010) Artesunate versus Quinine in the Treatment of Severe Falciparum Malaria in African Children (AQUAMAT): An Open-Label, Randomised Trial. Lancet, 376, 1647-1657. https://doi.org/10.1016/S0140-6736(10)61924-1

[21] Dondorp, A., Nosten, F., Stepniewska, K., Day, N. and White, N. (2005) South East Asian Quinine Artesunate Malaria Trial (SEAQUAMAT) Group. Artesunate versus Quinine for Treatment of Severe Falciparum Malaria: A Randomised Trial. Lancet, 366, 717-725. https://doi.org/10.1016/S0140-6736(05)67176-0

[22] Sinclair, D., Donegan, S. and Lalloo, D.G. (2011) Artesunate versus Quinine for Treating Severe Malaria. The Cochrane Collaboration, Issue 3, 55.

\section{Submit or recommend next manuscript to SCIRP and we will provide best} service for you:

Accepting pre-submission inquiries through Email, Facebook, LinkedIn, Twitter, etc. A wide selection of journals (inclusive of 9 subjects, more than 200 journals)

Providing 24-hour high-quality service

User-friendly online submission system

Fair and swift peer-review system

Efficient typesetting and proofreading procedure

Display of the result of downloads and visits, as well as the number of cited articles

Maximum dissemination of your research work

Submit your manuscript at: http://papersubmission.scirp.org/

Or contact ojped@scirp.org 